\title{
Use of International Criticality Safety Benchmark Evaluation Project Benchmarks for the Validation of CSAS26 (Scale 4.4a) for Configurations of Low-Enriched Uranium
}

\author{
Óscar Zurrón,* Guillermo Sánchez, and Carolina Álvaro \\ ENUSA Industrias avanzadas \\ Salamanca, Spain
}

Received November 11, 2002

Accepted January 29, 2003

\begin{abstract}
As an example of the application of the International Criticality Safety Benchmark Evaluation Project (ICSBEP) work to the nuclear industry, the validation of the control module CSAS26 of SCALE 4.4a for criticality calculations on a personal computer platform is presented. This work has been done using the models of critical experiments being compiled by the Organisation for Economic Co-operation and Development/Nuclear Energy Agency (OECD/NEA) since 1992. The description and results of this compilation were first presented during the Fifth International Conference on Nuclear Criticality Safety (ICNC'95). Out of 2881 critical configurations included in the latest edition (September 2002) of the ICSBEP "International Handbook of Evaluated Criticality Safety Benchmark Experiments," NEA/NSC/ DOC(95)03, OECD/NEA, 131 have been selected for the CSAS26 validation. The selected critical experiments have characteristics similar to the systems to be simulated with CSAS26 for low-enriched uranium (LEU) fuel fabrication applications. They represent both homogeneous configurations and hexagonally pitched rod lattices of low-enriched (from 1.60 to $5.00 \mathrm{wt} \%{ }^{235} \mathrm{U}$ ) $\mathrm{UO}_{2}$ with several absorbers. The statistical uncertainties related to the application of CSAS26 for criticality calculations are also evaluated. The great number of cases involved allows an exhaustive statistical treatment of the data, including the analysis of correlations related to the type of system being simulated. The statistical uncertainties found are very small. As a result, the module CSAS26 is considered as a quite suitable calculational method for application to criticality safety analysis at LEU facilities.
\end{abstract}

\section{INTRODUCTION}

As established in the standard ANSI/ANS-8.1-1998 (Ref. 1), any calculational method used to analyze the behavior of systems containing fissionable material has to be validated to determine the bias and related uncertainties. This process allows normalization of the method within its range of applicability in such a way that it is able to correctly predict criticality conditions within the limits of the uncertainties related both to the bias and to the $k_{\text {eff }}$ of each particular case. Thus, the present paper presents the results and methodology applied for the validation of the control module CSAS26 (BONAMI/

*E-mail: ozc@fab.enusa.es
NITAWL-II/KENO-VI) of SCALE 4.4a to execute criticality calculations on a personal computer platform.

One of the most commonly used validation strategies consists of simulating critical configurations by using the calculational method intended to be validated and comparing the results to the previously known experimental values. Following this approach and starting with the experimental data from Ref. 2 , the next sections of this paper present the results obtained from the simulation of 131 critical configurations performed using the control module CSAS26 with the 44-group library ENDF/B-V. Calculations were executed on a Pentium II/450-MHz machine with Windows NT 4.0 Terminal Server OS. Afterward, these results are compared to the benchmark value of each critical configuration, thus obtaining the bias of the method and the related statistical uncertainties. 


\section{SELECTION OF THE EXPERIMENTAL MATRIX}

Since 1992, the Organisation for Economic Cooperation and Development/Nuclear Energy Agency has assembled a huge compilation of critical experiments whose description and results were first presented during the Fifth International Conference on Nuclear Criticality Safety, held at Albuquerque, New Mexico, in September 1995. This compilation is included with a standardized format in Ref. 2 and constitutes a valuable tool for the validation of calculational methods used for criticality safety assessment purposes.

Out of 2881 critical experiments included in the latest edition of Ref. 2 (September 2002), 131 have been selected for this work. The selection criteria rely on fitting the experimental features to those of the systems to be simulated with CSAS26 in low-enriched uranium (LEU) fuel fabrication applications and, in particular, to the different configurations applicable to VVER designs during both the ceramic and mechanical stages of the fabrication process. Thus, the selected experimental matrix covers thermal, homogeneous, and heterogeneous configurations (hexagonally pitched lattices of rods) of low-enriched $\mathrm{UO}_{2}$ (from 1.6 to $5.0 \mathrm{wt} \%{ }^{235} \mathrm{U}$ ) with light water moderation and in the presence of several burnable absorbers, such as $\mathrm{B}, \mathrm{Eu}$, or $\mathrm{Gd}$.

\section{II.A. VVER Experiments, KFKI (Budapest)}

Between 1972 and 1990, the VVER-design user countries established a Temporary International Collective (TIC), led by Hungary, with the objective of performing joint experiments and code development in the scope of such fuel design. The experimental basis of TIC was the critical assembly ZR-6(M), operated by the Central Research Institute for Physics of the Hungarian Academy of Sciences (KFKI, Budapest). ${ }^{3,4}$

The experimental configurations studied in the ZR6(M) critical assembly used $\mathrm{UO}_{2}$ rods of several enrichments, between 1.60 and $4.40 \mathrm{wt} \%{ }^{235} \mathrm{U}$. In some cases, these configurations included different types of absorber rods (with $\mathrm{B}, \mathrm{Eu}$, or $\mathrm{Gd}$ ) and different concentrations of $\mathrm{H}_{3} \mathrm{BO}_{3}$ dissolved in the moderator (light water). By changing these parameters, as well as the geometry of the configurations or their temperature, up to a total of 334 configurations were studied, 165 of which are included in Ref. 3 and 69 of which are included in Ref. 4. In all of them, criticality was achieved by modifying the level of the water.

Out of the total number of critical configurations included in Refs. 3 and 4, 98 have been selected for the validation of CSAS26. They can be classified into the following categories:

Category 1. regular lattices (group LCT15A, cases 1 through 55 of Table I), which are those containing only $\mathrm{UO}_{2}$ rods of the same enrichment $^{3}$; see Fig. 1

Category 2. regular lattices with mixed enrichment (group LCT15B, cases 56, 57, and 58 of Table I) (Ref. 3). Figure 2 shows a typical scheme of the cross section for this lattice's category. Note how rods of a second enrichment are distributed around a regular lattice making a cylindrical envelope.

Category 3. lattices with point perturbations (groups LCT15C, cases 59 through 77 and LCT36, cases 80 through 98 of Table I), built up from regular lattices in which some $\mathrm{UO}_{2}$ rods have been substituted by holes or absorber rods ${ }^{3,4}$ (Fig. 3)

Category 4. combinations of categories 1 and 2 (group LCT15D, cases 78 and 79 of Table I) (Ref. 3). Figure 4 shows a typical scheme. The two main zones of different enrichment are clearly identified as well as the location of holes and absorber rods in the central area of the configuration.

\section{II.B. Regular Lattices of $U(5 \%) \mathrm{O}_{2}$, RRC KI (Moscow)}

In 1961, a series of critical experiments involving hexagonally pitched lattices of cylindrical rods with low enrichment $\left(\sim 5 \mathrm{wt} \%{ }^{235} \mathrm{U}\right)$ was performed in the Russian Research Center "Kurchatov Institute" (RRC KI). These lattices were moderated by light water with or without $\mathrm{H}_{3} \mathrm{BO}_{3}$ (Refs. 5, 6, and 7). Criticality was achieved by changes in the total number of rods, the pitch, or the level of the water.

Out of 16 configurations included in Refs. 5, 6, and 7,15 were selected for the validation of CSAS26. Attending to the type of cladding, the selected lattices can be classified into the following categories:

Category 1. lattices with stainless steel cladding (group LCT19, cases 99 and 100 of Table I) (Ref. 5)

Category 2. lattices with zirconium cladding (groups LCT20, cases 101 through 107 and LCT31, cases 108 through 113 of Table I) (Refs. 6 and 7).

All these 15 lattices follow similar schemes as those shown in Fig. 1.

\section{II.C. MARACAS Program: Homogeneous $U(5 \%) \mathrm{O}_{2}$ Powder Configurations, IPSN (Valduc)}

This set of experiments was carried out between 1983 and 1987 in a critical facility at Valduc, France, run by 
TABLE I

Summary of Results

\begin{tabular}{|c|c|c|c|c|c|c|c|c|c|c|c|}
\hline $\begin{array}{c}\text { Group } \\
\text { (Reference) }\end{array}$ & $I_{\exp (i)}$ & Case & Configuration & $k_{m(i)}$ & $\sigma_{m(i)}$ & $\begin{array}{c}\text { Group } \\
\text { (Reference) }\end{array}$ & $I_{\exp (i)}$ & Case & Configuration & $k_{m(i)}$ & $\sigma_{m(i)}$ \\
\hline \multirow[t]{6}{*}{$\begin{array}{l}\text { LCT15A } \\
\text { (3) }\end{array}$} & \multirow[t]{6}{*}{0.0030} & \multirow{6}{*}{$\begin{array}{r}1 \\
2 \\
3 \\
4 \\
5 \\
6 \\
7 \\
8 \\
9 \\
10 \\
11 \\
12 \\
13 \\
14 \\
15 \\
16 \\
17 \\
18 \\
19 \\
20 \\
21 \\
22 \\
23 \\
24 \\
25 \\
26 \\
27 \\
28 \\
29 \\
30 \\
31 \\
32 \\
33 \\
34 \\
35 \\
36 \\
37 \\
38 \\
39 \\
40 \\
41 \\
12\end{array}$} & \multirow{6}{*}{$\begin{array}{c}175 / 175 \\
174 / 174 \\
154 / 154 \\
246 / 246 \\
173 / 173 \\
52 / 23 \\
172 a / 172 \\
51 / 24 \\
171 \mathrm{a} / 171 \\
170 / 170 \\
169 / 169 \\
158 / 155 \\
162 / 161 \\
161 / 161 \\
163 / 161 \\
247 / 247 \\
195 / 39 \\
194 / 194 \\
193 / 193 \\
192 / 192 \\
188 / 40 \\
191 / 191 \\
212 / 212 \\
213 / 213 \\
214 / 214 \\
220 / 220 \\
215 / 215 \\
216 / 216 \\
217 / 217 \\
218 / 218 \\
219 / 219 \\
233 / 233 \\
232 / 232 \\
234 / 234 \\
235 / 235 \\
236 / 236 \\
237 / 237 \\
230 / 230 \\
229 / 229 \\
225 / 225 \\
221 / 221 \\
224 / 224 \\
223 / 223 \\
208 / 208 \\
207 / 207 \\
206 / 206 \\
205 / 205 \\
204 / 204 \\
203 / 203 \\
202 / 202 \\
201 / 201 \\
200 / 200 \\
199 / 199 \\
110 / 110 \\
164 / 110 \\
\end{array}$} & \multirow{6}{*}{$\begin{array}{l}0.9994 \\
1.0012 \\
0.9950 \\
0.9977 \\
0.9978 \\
0.9973 \\
0.9994 \\
0.9977 \\
0.9978 \\
0.9972 \\
0.9980 \\
0.9945 \\
0.9947 \\
1.0019 \\
0.9981 \\
1.0039 \\
0.9953 \\
0.9924 \\
0.9953 \\
0.9968 \\
0.9927 \\
0.9930 \\
0.9991 \\
0.9984 \\
1.0012 \\
0.9977 \\
0.9978 \\
0.9960 \\
1.0015 \\
0.9989 \\
1.0002 \\
1.0034 \\
1.0029 \\
1.0019 \\
1.0120 \\
1.0020 \\
1.0046 \\
0.9968 \\
0.9977 \\
0.9972 \\
1.0010 \\
1.0013 \\
0.9965 \\
1.0060 \\
1.0026 \\
1.0060 \\
1.0032 \\
1.0055 \\
1.0049 \\
1.0015 \\
1.0029 \\
1.0033 \\
1.0030 \\
0.9959 \\
0.9943 \\
\end{array}$} & \multirow{6}{*}{$\begin{array}{l}0.0014 \\
0.0015 \\
0.0014 \\
0.0014 \\
0.0014 \\
0.0014 \\
0.0016 \\
0.0015 \\
0.0015 \\
0.0014 \\
0.0013 \\
0.0015 \\
0.0014 \\
0.0013 \\
0.0014 \\
0.0012 \\
0.0014 \\
0.0014 \\
0.0013 \\
0.0013 \\
0.0013 \\
0.0013 \\
0.0016 \\
0.0014 \\
0.0017 \\
0.0016 \\
0.0015 \\
0.0016 \\
0.0013 \\
0.0014 \\
0.0015 \\
0.0013 \\
0.0014 \\
0.0012 \\
0.0013 \\
0.0013 \\
0.0013 \\
0.0013 \\
0.0015 \\
0.0016 \\
0.0016 \\
0.0017 \\
0.0019 \\
0.0013 \\
0.0015 \\
0.0016 \\
0.0013 \\
0.0015 \\
0.0014 \\
0.0015 \\
0.0015 \\
0.0016 \\
0.0013 \\
0.0015 \\
0.0014\end{array}$} & $\begin{array}{l}\text { LCT15C } \\
\text { (3) }\end{array}$ & 0.0030 & $\begin{array}{l}59 \\
60 \\
61 \\
62 \\
63 \\
64 \\
65 \\
66 \\
67 \\
68 \\
69 \\
70 \\
71 \\
72 \\
73 \\
74 \\
75 \\
76 \\
77\end{array}$ & $\begin{array}{c}158-1 / 155 \\
158-2 / 155 \\
158-3 / 155 \\
158-4 / 155 \\
158-5 / 155 \\
158-6 / 155 \\
158-7 / 155 \\
155 / 155 \\
155-1 / 155 \\
156 / 155 \\
244 / 244 \\
243 / 243 \\
156-1 / 155 \\
1244 / 244 \\
157 / 155 \\
245 / 244 \\
189 / 189 \\
242 / 242 \\
190 / 190\end{array}$ & $\begin{array}{l}0.9922 \\
1.0000 \\
0.9974 \\
0.9944 \\
0.9981 \\
0.9979 \\
0.9984 \\
1.0084 \\
1.0046 \\
1.0012 \\
1.0002 \\
0.9995 \\
0.9974 \\
0.9939 \\
0.9962 \\
0.9932 \\
0.9941 \\
1.0022 \\
0.9995\end{array}$ & $\begin{array}{l}0.0017 \\
0.0016 \\
0.0015 \\
0.0013 \\
0.0018 \\
0.0014 \\
0.0016 \\
0.0013 \\
0.0015 \\
0.0016 \\
0.0014 \\
0.0015 \\
0.0016 \\
0.0014 \\
0.0016 \\
0.0014 \\
0.0013 \\
0.0015 \\
0.0016\end{array}$ \\
\hline & & & & & & $\begin{array}{l}\text { LCT15D } \\
\text { (3) }\end{array}$ & 0.0030 & $\begin{array}{l}78 \\
79\end{array}$ & $\begin{array}{l}197 / 197 \\
198 / 198\end{array}$ & $\begin{array}{l}1.0044 \\
1.0036\end{array}$ & $\begin{array}{l}0.0015 \\
0.0013\end{array}$ \\
\hline & & & & & & $\begin{array}{l}\text { LCT36 } \\
(4)\end{array}$ & 0.0090 & $\begin{array}{l}80 \\
81 \\
82 \\
83 \\
84 \\
85 \\
86 \\
87 \\
88 \\
89 \\
90 \\
91 \\
92 \\
93 \\
94 \\
95 \\
96 \\
97 \\
98\end{array}$ & $\begin{array}{l}293 / 293 \\
294 / 294 \\
295 / 295 \\
296 / 296 \\
297 / 297 \\
298 / 298 \\
299 / 299 \\
302 / 302 \\
303 / 303 \\
304 / 304 \\
305 / 305 \\
306 / 306 \\
307 / 307 \\
308 / 308 \\
309 / 309 \\
310 / 310 \\
311 / 311 \\
312 / 312 \\
313 / 313\end{array}$ & $\begin{array}{l}0.9974 \\
0.9982 \\
0.9946 \\
0.9932 \\
0.9964 \\
0.9952 \\
0.9975 \\
0.9940 \\
0.9969 \\
0.9950 \\
0.9968 \\
0.9988 \\
0.9975 \\
0.9981 \\
0.9927 \\
0.9973 \\
0.9949 \\
0.9976 \\
0.9952\end{array}$ & $\begin{array}{l}0.0014 \\
0.0016 \\
0.0016 \\
0.0015 \\
0.0017 \\
0.0017 \\
0.0014 \\
0.0015 \\
0.0016 \\
0.0016 \\
0.0017 \\
0.0015 \\
0.0016 \\
0.0016 \\
0.0015 \\
0.0016 \\
0.0015 \\
0.0018 \\
0.0014\end{array}$ \\
\hline & & & & & & $\begin{array}{c}\text { LCT19 } \\
(5)\end{array}$ & $\begin{array}{l}0.0058 \\
0.0061\end{array}$ & $\begin{array}{r}99 \\
100\end{array}$ & $\begin{array}{l}2 \\
3\end{array}$ & $\begin{array}{l}1.0062 \\
1.0054\end{array}$ & $\begin{array}{l}0.0018 \\
0.0012\end{array}$ \\
\hline & & & & & & $\begin{array}{l}\text { LCT20 } \\
(6)\end{array}$ & 0.0061 & $\begin{array}{l}101 \\
102 \\
103 \\
104 \\
105 \\
106 \\
107\end{array}$ & $\begin{array}{l}1 \\
2 \\
3 \\
4 \\
5 \\
6 \\
7\end{array}$ & $\begin{array}{l}0.9972 \\
0.9998 \\
1.0029 \\
1.0033 \\
1.0018 \\
1.0039 \\
1.0043\end{array}$ & $\begin{array}{l}0.0013 \\
0.0015 \\
0.0015 \\
0.0016 \\
0.0014 \\
0.0015 \\
0.0014\end{array}$ \\
\hline & & & & & & $\begin{array}{l}\text { LCT31 } \\
\text { (7) }\end{array}$ & 0.0045 & $\begin{array}{l}108 \\
109\end{array}$ & $\begin{array}{l}1 \\
2\end{array}$ & $\begin{array}{l}0.9880 \\
0.9912\end{array}$ & $\begin{array}{l}0.0014 \\
0.0016\end{array}$ \\
\hline$\underset{(3)}{\text { LCT15B }}$ & 0.0030 & $\begin{array}{l}56 \\
57 \\
58\end{array}$ & $\begin{array}{l}160 / 160 \\
166 / 166 \\
231 / 231\end{array}$ & $\begin{array}{l}0.9960 \\
0.9956 \\
0.9952\end{array}$ & $\begin{array}{l}0.0014 \\
0.0015 \\
0.0012\end{array}$ & & & $\begin{array}{l}110 \\
112 \\
113\end{array}$ & $\begin{array}{l}5 \\
4 \\
5 \\
6\end{array}$ & $\begin{array}{l}0.9939 \\
0.9895 \\
0.9909 \\
0.9933\end{array}$ & $\begin{array}{l}0.0019 \\
0.0015 \\
0.0016 \\
0.0014\end{array}$ \\
\hline
\end{tabular}

(Continued) 
TABLE I (Continued)

\begin{tabular}{|c|c|c|c|c|c|}
\hline $\begin{array}{c}\text { Group } \\
\text { (Reference) }\end{array}$ & $I_{\exp (i)}$ & Case & Configuration & $k_{m(i)}$ & $\sigma_{m(i)}$ \\
\hline \multirow[t]{5}{*}{$\begin{array}{l}\text { LCT49 } \\
(8)\end{array}$} & 0.0034 & $\begin{array}{l}114 \\
115 \\
116 \\
117\end{array}$ & $\begin{array}{l}R 2-2 R(6,6) \\
R 1-3 R(6,6) \\
R 2-3 R(6,6) \\
R 3-3 R(6,6)\end{array}$ & $\begin{array}{l}1.0004 \\
1.0020 \\
1.0002 \\
1.0027\end{array}$ & $\begin{array}{l}0.0015 \\
0.0013 \\
0.0016 \\
0.0014\end{array}$ \\
\hline & 0.0042 & $\begin{array}{l}118 \\
119 \\
120 \\
121\end{array}$ & $\begin{array}{l}R 2-2 R(4,5) \\
R 1-3 R(4,5) \\
R 1-2 R(5,5) \\
R 2-2 R(5,5)\end{array}$ & $\begin{array}{l}0.9971 \\
1.0005 \\
1.0008 \\
1.0004\end{array}$ & $\begin{array}{l}0.0015 \\
0.0013 \\
0.0018 \\
0.0013\end{array}$ \\
\hline & 0.0037 & $\begin{array}{l}122 \\
123 \\
124 \\
125\end{array}$ & $\begin{array}{l}\mathrm{R} 2-2 \mathrm{R}(4,3) \\
\mathrm{R} 1-3 \mathrm{R}(4,3) \\
\mathrm{R} 1-2 \mathrm{R}(4,4) \\
\mathrm{R} 2-2 \mathrm{R}(4,4)\end{array}$ & $\begin{array}{l}0.9982 \\
1.0003 \\
0.9981 \\
0.9994\end{array}$ & $\begin{array}{l}0.0013 \\
0.0015 \\
0.0015 \\
0.0014\end{array}$ \\
\hline & 0.0036 & $\begin{array}{l}126 \\
127 \\
128 \\
129 \\
130\end{array}$ & $\begin{array}{l}\text { R2-3R }(4,4) \text { con } \\
\text { R3-3R }(4,4) \text { con } \\
\text { R2-4R }(4,4) \text { con } \\
\text { R1-2R }(5,5) \text { che } \\
\text { R2-2R }(5,5) \text { che }\end{array}$ & $\begin{array}{l}1.0037 \\
1.0028 \\
0.9974 \\
0.9999 \\
0.9999\end{array}$ & $\begin{array}{l}0.0015 \\
0.0016 \\
0.0014 \\
0.0015 \\
0.0015\end{array}$ \\
\hline & 0.0030 & 131 & $\mathrm{R} 2-1 \mathrm{R}(3,3) \mathrm{mod}$ & 1.0017 & 0.0014 \\
\hline
\end{tabular}

the Safety and Criticality Research Service of the Institute of Nuclear Protection and Safety (IPSN). The experimental basis of this program was the split-table testing device called "MARACAS" (Ref. 8). The experiments included involved low-water-moderated and low-enriched $\left(5 \mathrm{wt} \%{ }^{235} \mathrm{U}\right)$ uranium dioxide powder assemblies with polythene reflection. These assemblies consisted of boxes

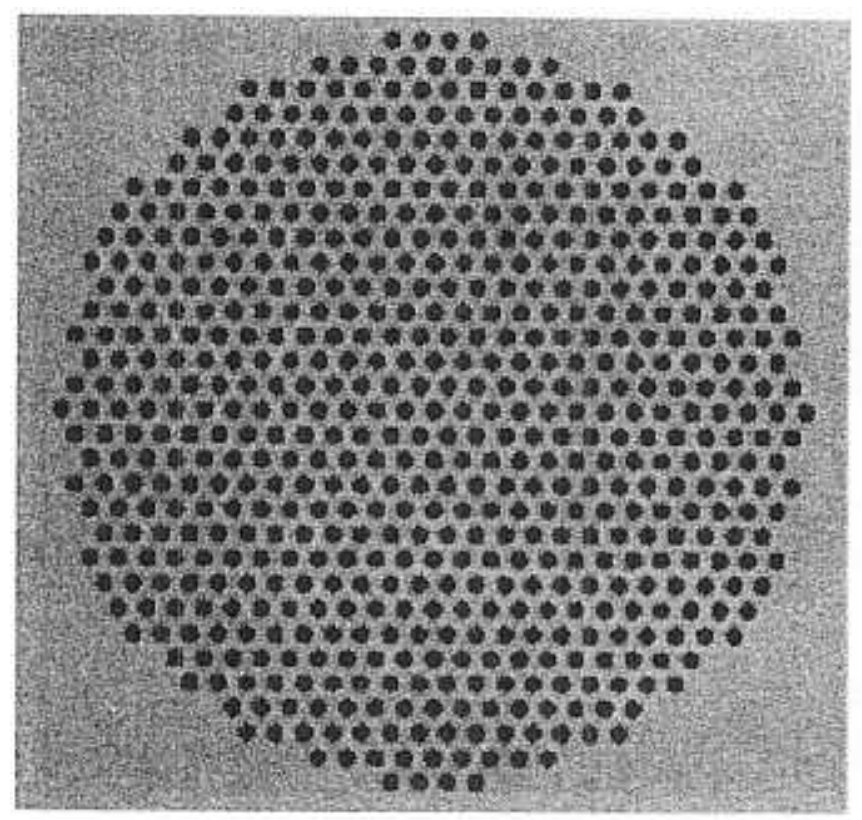

Fig. Regular lattice cross section.

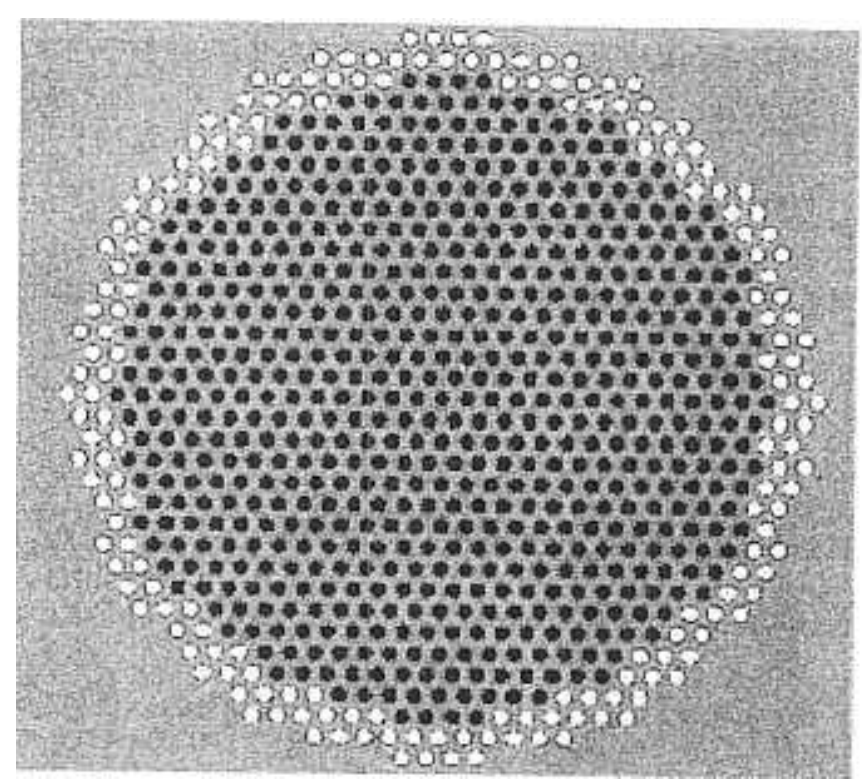

Fig. 2. Mixed-enrichment lattice cross section.

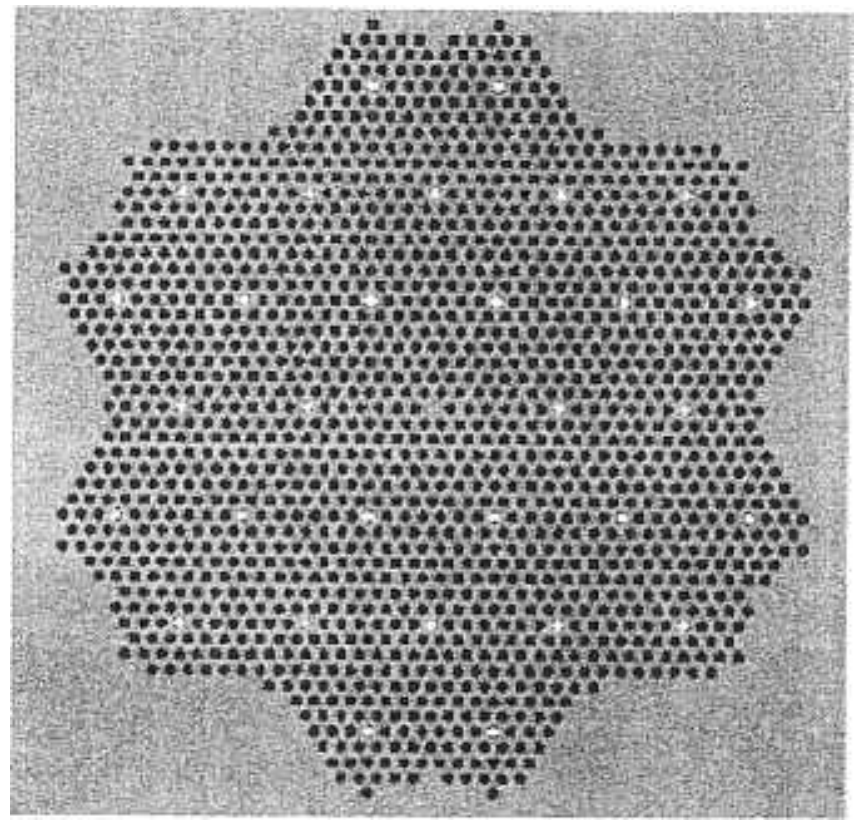

Fig. 3. Cross section of a lattice with point perturbations.

filled with moistened $\mathrm{UO}_{2}$ powder that were stacked on one of the two halves of the MARACAS device. All the experiments were subcritical approaches extrapolated to critical by measuring distances between the two halves of the split table.

All 18 configurations included in Ref. 8 were chosen for the CSAS26 validation. They comprised the group LCT49 of Table I and can be classified as follows: 


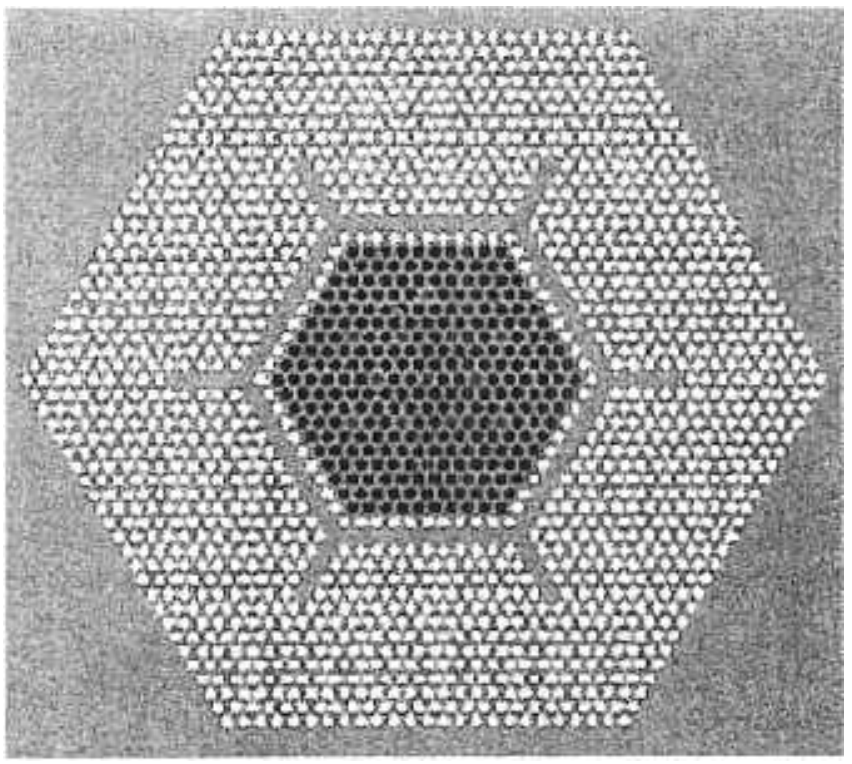

Fig. 4. Cross section of category 4 lattice type on $\mathrm{p}$. $\mathrm{xxx}$

1. configurations with the same $\mathrm{H} / \mathrm{U}$ ratio, equal to 2.0 (cases 114 through 117), 2.5 (cases 118 through 121), or 3.0 (cases 122 through 125)

2. configurations with mixed $\mathrm{H} / \mathrm{U}$ ratio, assemblies with both boxes of $\mathrm{H} / \mathrm{U}=2.0$ and $\mathrm{H} / \mathrm{U}=3.0$ together, arranged in concentric layers (cases 126, 127 , and 128) or as a checkerboard (cases 129 and 130)

3. modular configuration, comprising boxes with $\mathrm{H} / \mathrm{U}$ ratios of 2.0 and 3.0 , empty boxes and boxes with absorber crossing blades (case 131).

\section{ANALYSIS OF THE RESULTS}

The selected 131 critical experiments have been simulated by means of CSAS26 with the 44-group library ENDF/B-V. As a result of this simulation, the multiplication factors $k_{m(i)}(i=1, \ldots, 131)$ shown in Table I are obtained, along with their respective errors of the mean, designated as $\sigma_{m(i)}$. A total of 250 generations of 1500 neutrons each were run for each calculation. In order to minimize the variance of the results, the first 50 generations were skipped in all calculations. These are the values of $k_{m(i)}$ and $\sigma_{m(i)}$ that are included in Table I.

In all cases, the experimental value of $k_{\text {eff }}$ is assumed to be 1.0000 as specified in the original references, though its accuracy depends on the configuration. Thus, the experiments performed under similar conditions are grouped in Table 1 . The accuracy $I_{\exp (i)}$ of the experimental $k_{\text {eff }}$ from the reference for each group of similar experiments is also indicated in Table I. The col- umn "Configuration," which is the identification of the configuration in the original references, is included to link each case with its related experimental configuration.

The standard ANSI/ANS-8.17-1997 (Ref. 9) gives guidance to determine an upper subcritical limit (USL) from the bias and uncertainties related to the calculational method being used. More specifically, Ref. 9 states that to assure subcriticality by computing the neutron multiplication factor $k_{p}$ of a particular system, the following expression shall be fulfilled:

$$
k_{p}+\left|\Delta k_{p}\right| \leq \mathrm{USL} \equiv k_{c}-\left|\Delta k_{c}\right|-\left|\Delta k_{m}\right|,
$$

where

$$
\begin{aligned}
k_{c}= & \begin{array}{r}
\text { mean } k_{\text {eff }} \text { that results from the simulation of } \\
\text { critical experiments using the code intended } \\
\\
\text { to be validated }
\end{array} \\
\Delta k_{c}= & \text { uncertainty in the determination of } k_{c} \\
\Delta k_{p}= & \text { uncertainty related to the computation of } k_{p} \\
\Delta k_{m}= & \text { (arbitrary) value required to ensure an accept- } \\
& \text { able margin of subcriticality. }
\end{aligned}
$$

Note that expression (1) can be rewritten as

$$
k \equiv k_{p}+\left(1-k_{c}\right)+\left|\Delta k_{c}\right|+\left|\Delta k_{p}\right| \leq 1-\left|\Delta k_{m}\right| \text {, }
$$

which allows one to define $k$, the maximum allowable value for the $k_{\text {eff }}$ of the system subjected to study as a function of the required $\Delta k_{m}$.

The values of $k_{c}$ and $\Delta k_{c}$ must be estimated from the results of the simulation of critical experiments. Checks on correlations of the results related to the different parameters taken into account (enrichment, pitch, etc.) in the simulated systems were carried out; no trends were observed. Thus, all 131 cases in Table I are considered as an unique sampling group and were checked for normality applying the $D^{\prime}$ test as recommended by Ref. 10 when the sample size $n>50$. Once normality of the population is assumed, the estimator of $k_{c}$ can be computed using the arithmetic mean of the individual $k_{m(i)}$ :

$$
\tilde{k}_{c}=\frac{\sum_{i=1}^{n} k_{m(i)}}{n} .
$$

where $n=131$. The term $\Delta k_{c}$ is then computed from the sample variance

$$
s_{c}^{2}=\frac{\sum_{i=1}^{n}\left(k_{m(i)}-\tilde{k}_{c}\right)^{2}}{n-1}
$$

and the internal variance of the data $\sigma_{c}^{2}$, determined from the quadratic means of the deviations $\sigma_{m(i)}$ and of the uncertainties $I_{\exp (i)}$. The reference papers included in Ref. 2 describe the confidence levels used to calculate the experimental uncertainty only for cases 114 through 
131, for which $I_{\exp (i)}=3 \sigma_{\exp (i)}$ (Ref. 8). For the rest of the cases, it is assumed that the experimental uncertainties are given for a centered interval and at a $95 \%$ confidence level. ${ }^{11}$ That is, for $i=1, \ldots, 113, I_{\exp (i)}=2 \sigma_{\exp (i)}$ is taken. Then,

$$
\sigma_{c}^{2}=\frac{1}{n} \sum_{i=1}^{n} \sigma_{m(i)}^{2}+\frac{1}{n}\left(\sum_{i=1}^{113} \frac{I_{\exp (i)}^{2}}{4}+\sum_{i=1.4}^{131} \frac{I_{\exp (i)}^{2}}{9}\right)
$$

Taking into account the rule for the addition of variances of statistically independent random variables, we have

$$
\left|\Delta k_{c}\right|=K_{c} \sqrt{s_{c}^{2}+\sigma_{c}^{2}},
$$

where the coverage factor $K_{c}$ depends on the significance level (i.e., probability) $P=1-\alpha$ desired to compute $k_{c}$.Applying the criteria established in the standard, ${ }^{12}$ the USL must be determined as a 95/95 one-sided tolerance limit. Mathematically, the problem is to find a $K_{c}$ such that

$$
\operatorname{Pr}\left\{\operatorname{Pr}\left(X \leq \bar{x}+K_{c} s\right) \geq P\right\}=\gamma,
$$

where $X$ follows a normal distribution and $P$ and $\gamma$ are the specified probabilities, both equal to 0.95 . Then, $K_{c}$ is the quantile verifying

$$
\operatorname{Pr}\left\{T_{f} \leq K_{c} \sqrt{n} \mid C_{p} \sqrt{n}\right\}=\gamma,
$$

where $T_{f}$ is the noncentral $-t$ Student's distribution with $f=n-1$ degrees of freedom and $C_{p}$ is the $z_{1-\alpha}$ value of the standard normal distribution. In our case $f=130$, $\alpha=0.05$, and $\gamma=0.95$. Upon these conditions, $K_{c}=$ 1.888 .

The term $\Delta k_{p}$, related to the calculation uncertainty of a particular case, is determined from the calculation error $\sigma_{p}$ for the estimator $\tilde{k}_{p}$ of the $k_{\text {eff }}$ of the actual case. Both values are supplied by CSAS26. This uncertainty is computed by multiplying $\sigma_{p}$ by the coverage factor $K_{p}$ related to the desired significance level. Taking into consideration that both $\tilde{k}_{p}$ and $\sigma_{p}$ are computed after a large number of Monte Carlo generations (250 at least) whose $k_{\text {eff }}$ 's follow a normal distribution, the upper limit of the one-sided $\gamma$ confidence interval of the estimator $\tilde{k}_{p}$ is given taking $K_{p}=z_{1-\alpha}$, where $z_{1-\alpha}$ is the quantile of the standard normal distribution corresponding to the desired confidence level. If $\alpha=0.05, z_{0.95}=1.645$. Conservatively, $K_{p}=2$ is assumed, and thus, $\left|\Delta k_{p}\right|=2 \sigma_{p}$.

This new term must be added to Eq. (6) following the variance's addition rule, which leads to

$$
\left|\Delta k_{p}\right|+\left|\Delta k_{c}\right|=\sqrt{K_{p}^{2} \sigma_{p}^{2}+K_{c}^{2}\left(s_{c}^{2}+\sigma_{c}^{2}\right)},
$$

which allows rewriting Eq. (2) as

$$
\begin{aligned}
k= & k_{p}+\left(1-k_{c}\right)+\sqrt{K_{p}^{2} \sigma_{p}^{2}+K_{c}^{2}\left(s_{c}^{2}+\sigma_{c}^{2}\right)} \\
& \leq 1-\left|\Delta k_{m}\right| .
\end{aligned}
$$

TABLE II

\begin{tabular}{|c|c|c|c|}
\hline \multicolumn{4}{|c}{ Parameters $\tilde{k}_{c}, s_{c}^{2}$, and $\sigma_{c}^{2}$} \\
\hline$\tilde{k}_{c}$ & $s_{c}^{2}$ & $\sigma_{c}^{2}$ & $s_{c}^{2}+\sigma_{c}^{2}$ \\
\hline 0.9988 & $1.6322 \mathrm{E}-05^{\mathrm{a}}$ & $7.5635 \mathrm{E}-06$ & $2.3886 \mathrm{E}-05$ \\
\hline
\end{tabular}

${ }^{\mathrm{a}}$ Read as $1.6322 \times 10^{-5}$.

Table II shows the values of $\tilde{k}_{c}, s_{c}^{2}$, and $\sigma_{c}^{2}$ resulting from the application of expressions (3), (4), and (5).

\section{CONCLUSIONS}

Substituting the numerical values of the parameters in Eq. (10) and $k_{p}$ and $k_{c}$ by their estimators, the final expression, which compares the maximum allowable value for the $k_{\text {eff }}$ of the system subjected to study with the required $\Delta k_{m}$, is obtained:

$$
\begin{aligned}
k= & \tilde{k}_{p}+0.0012+\sqrt{4 \sigma_{p}^{2}+8.5142 \times 10^{-5}} \\
& \leq 1-\left|\Delta k_{m}\right|
\end{aligned}
$$

where $\tilde{k}_{p}$ and $\sigma_{p}$ are the values supplied by CSAS26 for the $k_{\text {eff }}$ of the particular system and for its standard deviation, respectively, and $\Delta k_{m}$ is the additional (arbitrary) safety margin.

Finally, if the numerical values of Table II are substituted into Eq. (1), the expression for the USL as a function of $\Delta k_{m}$ is obtained:

$$
\mathrm{USL}=0.9896-\left|\Delta k_{m}\right|
$$

The results of the statistical approach described in this paper have been compared with the methodology stated in Ref. 13, which leads to the conclusion that both approaches give similar results. In fact, the USL, as stated by expression (12), is just $0.1 \%$ more conservative than the most pessimistic value obtained by means of the method described in Ref. 13, which gives an idea of how close the results obtained by both approaches are.

Expressions (11) and (12) stand for calculations performed with the 44-group ENDF/B-V library on systems with features similar to those of the critical configurations used for the present validation. Basically, such systems are thermal, homogeneous configurations and hexagonally pitched lattices of rods of LEU (enrichment below $5.0 \mathrm{wt} \%{ }^{235} \mathrm{U}$ ) with light water moderation. The uncertainties found are very small, so that CSAS26 is considered as a quite suitable calculational tool for application in LEU facilities. 


\section{REFERENCES}

1. "Nuclear Criticality Safety in Operations with Fissionable Material Outside Reactors," ANSI/ANS-8.1-1998, American Nuclear Society.

2. "International Handbook of Evaluated Criticality Safety Benchmark Experiments," NEA/NSC/DOC(95)03, Organisation for Economic Co-operation and Development/Nuclear Energy Agency (Sep. 2002).

3. "The VVER Experiments: Regular and Perturbed Hexagonal Lattices of Low Enriched $\mathrm{UO}_{2}$ Fuel Rods in Light Water," NEA/NSC/DOC(95)03/IV LEU-COMP-THERM-015 Rev 2, Organisation for Economic Co-operation and Development/ Nuclear Energy Agency (Sep. 2000).

4. "The VVER Experiments: Regular and Perturbed Hexagonal Lattices of Low Enriched $\mathrm{UO}_{2}$ Fuel Rods in Light WaterPart 2," NEA/NSC/DOC(95)03/IV LEU-COMP-THERM036 Rev. 0, Organisation for Economic Co-operation and Development/Nuclear Energy Agency (Sep. 1999).

5. "Water Moderated Hexagonally Pitched Lattices of $\mathrm{U}(5 \%) \mathrm{O}_{2}$ Stainless Steel Clad Fuel Rods," NEA/NSC/ DOC(95)03/IV LEU-COMP-THERM-019 Rev. 0, Organisation for Economic Co-operation and Development/Nuclear Energy Agency (Sep. 1997).

6. "Water Moderated Hexagonally Pitched Partially Flooded Lattices of $\mathrm{U}(5 \%) \mathrm{O}_{2}$ Zirconium Clad Fuel Rods, $1.3 \mathrm{~cm}$ Pitch," NEA/NSC/DOC(95)03/IV LEU-COMP-THERM-020 Rev. 0, Organisation for Economic Co-operation and Development/ Nuclear Energy Agency (Sep. 1997).
7. "Water Moderated Hexagonally Pitched Partially Flooded Lattices of $\mathrm{U}(5 \%) \mathrm{O}_{2}$ Zirconium Clad Fuel Rods, $0.8 \mathrm{~cm}$ Pitch," NEA/NSC/DOC(95)03/IV LEU-COMP-THERM-031 Rev. 0, Organisation for Economic Co-operation and Development/ Nuclear Energy Agency (Sep. 1997).

8. "Maracas Program: Polythene-Reflected Critical Configurations with Low-Enriched and Low Moderated Uranium Dioxide Powder, U(5) $\mathrm{O}_{2}$," NEA/NSC/DOC(95)03/IV LEUCOMP-THERM-049 Rev. 1, Organisation for Economic Cooperation and Development/Nuclear Energy Agency (Sep. 2000).

9. "Criticality Safety Criteria for the Handling, Storage and Transportation of LWR Fuel Outside Reactors," ANSI/ANS8.17-1997, American Nuclear Society.

10. "Assessment of the Assumption of Normality (Employing Individual Observed Values)," ANSI N15.15-1974, American National Standards Institute.

11. "Expresión de la incertidumbre de medida en las calibraciones," CEA-ENAC-LC102 Rev. 1, Commissariat à l'Energie Atomique (1998).

12. "Requisitos de criticidad para el diseño de bastidores de almacenamiento de piscinas de combustible," UNE 73-501-92, Asociación Espanola de Normalizacióny Certificación (1992).

13. "Criticality Benchmark Guide for Light Water Reactor Fuel in Transportation and Storage Packages,".NUREG/CR-6361, Oak Ridge National Laboratory (1997). 